\title{
RECIENTES DESARROLLOS DEL CONFLICTO DEL SAHARA OCCIDENTAL: AUTODETERMINACIÓN Y ESTATALIDAD
}

\section{Carlos RuIZ MiguEL*}

RESUMEN: A partir del derecho a la autodeterminación del pueblo del Sahara Occidental, el autor pone en la mesa de juicio los sucesos que han mediado y que han impedido tal acontecimiento, los cuales van, desde el impedimento en 1974 para la celebración de un referéndum de autodeterminación exigido por Naciones Unidas; el Plan de Paz de 1988, donde se contemplaba ya la creación de un censo poblacional para la celebración del citado referéndum, hasta el presente año, donde ya se ha publicado una lista provisional de votantes que prevé el triunfo de la opción independentista, todo esto enmarcado con un sólido fundamento teórico que plantea quién sería el titular del derecho en el supuesto de que se lograra la autodeterminación, quien ejercería tal derecho.

\begin{abstract}
Departing from the Western Saharan people's right to self-determination, the author analyses the events that have taken place and have prevented such right from being accomplished. These events date from the obstruction in 1974 to a self-determination referendum requested by United Nations; the Peace Plan in 1988, which provided for the creation of a population census for the mentioned referendum; to the present year, when a provisional voters list has been published, which anticipates the triumph of the pro-independence opposition, all this framed in a solid theoretical foundation, establishing who would be the holder of the right, in the event that the self-determination is accomplished.
\end{abstract}

* Profesor titular de derecho constitucional. Universidad Santiago de Compostela. 
SUMARIO: I. Introducción. II. La autodeterminación del pueblo del Sahara Occidental: ¿derecho revocable? III. La estatalidad de la República Árabe Saharaui Democrática. IV. Conclusiones.

\section{INTRODUCCIÓN}

Una de las más llamativas singularidades del conflicto sobre la última colonia africana, el Sahara Occidental, reside en el contraste que se produce en el mismo entre el "derecho" y la "política": por un lado, existen pronunciamientos jurídico-internacionales terminantes cuya puesta en práctica solucionaría de modo inmediato y sencillo esta ya larga disputa; por otro, encontramos innumerables maniobras políticas dirigidas a enervar la eficacia de las reglas jurídicas. Esta tensión entre el "derecho" y la "política" internacionales relativas al Sahara Occidental, acentuada en fechas recientes, se ha condensado principalmente en torno a dos cuestiones: en primer lugar, por la pretensión "política" de ignorar el "derecho" a la autodeterminación del pueblo del Sahara Occidental; en segundo lugar, por las maniobras "políticas" dirigidas a destruir el reconocimiento "jurídico" de la estatalidad del Sahara Occidental. Ambos polos de tensión plantean cuestiones jurídico-internacionales novedosas cuya solución tendrá gran importancia en el desarrollo futuro del derecho internacional. La primera cuestión es la de si el derecho a la autodeterminación del pueblo del Sahara Occidental puede ser sustituido por un arreglo político no previsto en el ordenamiento internacional y, como corolario, la de qué posición tiene tal derecho en ese ordenamiento. La segunda es la de si puede ponerse en cuestión la estatalidad de un pueblo por el hecho de que se halle pendiente un referéndum de autodeterminación.

\section{LA AUTODETERMINACIÓN DEL PUEBLO DEL SAHARA OCCIDENTAL: ¿DERECHO REVOCABLE?}

\section{Los informes del SG y el planteamiento del problema}

a. El conflicto del Sahara Occidental pudo haberse solucionado ya en 1974 si se hubiera celebrado el referéndum de autodeterminación que, exigido por Naciones Unidas, España se disponía a celebrar en la que era, entonces, su colonia. A tal efecto, en 1974 la potencia colonizadora ela- 
boró un censo que aún hoy constituye la base fundamental para la solución del problema. Marruecos intentó por todos los medios impedir la celebración del referéndum: inicialmente, consiguió paralizarlo tras conseguir que la Asamblea General aprobara en $1974^{1}$ la solicitud del envío de una misión visitadora al territorio, la demanda al Tribunal Internacional de Justicia un dictamen acerca de si existían elementos que pudieran impedir el referéndum y la petición a España que, mientras tanto, suspendiera los preparativos del mismo. El subsiguiente dictamen del Tribunal Internacional de Justicia ${ }^{2}$ fue contundente. Por un lado, declaró que nunca habían existido vínculos de "soberanía territorial" entre Marruecos y el Sahara Occidental, ya que no se declaró probado que Marruecos "haya ejercido una actividad estatal efectiva y exclusiva en el Sahara Occidental" y que lo máximo que había habido eran ciertos vínculos de vasallaje entre "ciertas, pero sólo ciertas" poblaciones nómadas del territorio y el sultán marroquí. ${ }^{3}$ En definitiva,

las conclusiones del Tribunal acerca de la naturaleza de los vínculos jurídicos entre el territorio (del Sahara Occidental) y respectivamente el Reino de Marruecos y el conjunto mauritano difieren sensiblemente de las opiniones emitidas a este respecto por Marruecos y Mauritania. En opinión del Tribunal, estos vínculos no implicaban ni soberanía territorial, ni co-soberanía, ni inclusión territorial en una entidad jurídica. ${ }^{4}$

Por otro lado, el Tribunal subrayaba que el dictamen requerido para ayudar a la Asamblea General de Naciones Unidas a pronunciarse "sobre las tesis de Marruecos y Mauritania según las cuales uno y otra habrían tenido con el Sahara Occidental vínculos jurídicos que pondrían en juego la integridad territorial de sus países", no afectaba ni modificaba "el derecho de las poblaciones del Sahara Occidental a la autodeterminación". 5

Apenas dos semanas después de que el dictamen del Tribunal privara de toda base jurídica a las pretensiones anexionistas marroquíes, tropas del ejército marroquí invadían el territorio por su frontera noreste, mientras por la frontera noroeste se escenificaba días después una ocupación pacífica mediante la "Marcha Verde". Esta ocupación militar y la subsi-

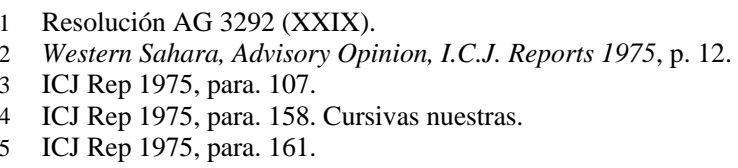


guiente guerra entre marroquíes y saharauis impidió la celebración del referéndum. El curso del conflicto, adverso tanto militar como diplomáticamente para Marruecos, y la amenaza de que la OUA admitiera en su seno a la República Saharaui llevó a que Hassán II aceptara en la cumbre de Nairobi de 1981 la celebración del referéndum en la colonia. El ingreso de la RASD en la OUA (amagado en 1982 y consumado en 1984), supuso la congelación del referéndum.

El desgaste de la guerra condujo a que en 1988 las partes en conflicto aceptaran un plan de paz que preveía un alto el fuego (realidad desde 1991) como paso previo para la celebración de un referéndum aún hoy pendiente. El plan de paz contemplaba la confección de un censo "sobre la base" del censo español de 1974 y la celebración del referéndum. Los obstáculos planteados principalmente por los intentos de Marruecos de ampliar todo lo posible el censo para incluir en él un número abrumador de ciudadanos marroquíes que pudieran decantar el resultado del lado del colonizador llevaron a un bloqueo del plan. Esta parálisis concluyó cuando, tras la mediación del representante especial del SG, James Baker III, se concluyeron en 1997 los acuerdos de Houston. ${ }^{7}$ Tras la publicación de la lista provisional de votantes el 17 de enero de 2000, que admite como saharauis a 86,381 candidatos de entre los más de 200,000 que se presentaron, se da como más que previsible el triunfo de la opción independentista en el referéndum. El rechazo de las Comisiones de Identificación de Naciones Unidas a los miles de candidatos que Marruecos ha intentado pasar por saharauis ha supuesto que este país haya bloqueado nuevamente el referéndum mediante la presentación de un número abusivo de recursos. La cuestión, jurídicamente, es clara: la inmensa mayoría de estos recursos no cumplen los requisitos pactados por las dos partes en los acuerdos de Nueva York de abril de 1999, para ser admitidos, ${ }^{8}$ pues en los recursos no se mencionan las "circunstancias, hechos nuevos o cualquier elemento de prueba" que no fueron conocidos por las Comisiones de Identificación en la primera instancia y que sirven para justificar la

6 Anexo en el informe del SG (S/21360) y que fue aprobado mediante la resolución S/RES/658 (1990) del Consejo de Seguridad.

7 Anexo del informe del SG (S/1997/742) y que fueron aprobados por la resolución S/RES/1133 (1997) del Consejo de Seguridad.

8 Protocolos "Procedimiento de recursos en el referéndum del Sahara Occidental" y "Directivas operacionales para la realización del proceso de apelaciones", contenidos en el anexo I al informe del SG UNDOC, S/1999/483/Add.1 de 27 de abril de 1999. Estos documentos fueron avalados por el Consejo de Seguridad en su resolución S/RES/1238 (1999), de 14 de mayo. 
decisión de admitir a trámite la apelación. ${ }^{9}$ Marruecos, sin embargo, violando el espíritu y la letra de los textos, pretende que dichos recursos sean admitidos y estimados.

b. Este nuevo bloqueo y la falta de voluntad política para aplicar los claros e inequívocos términos de las disposiciones acordadas por las partes y refrendadas por el Consejo de Seguridad es el que ha llevado al SG a formular, por primera vez desde que existe el conflicto, una sorprendente y gravísima propuesta. En su informe de 22 de mayo de 2000, tras dejar constancia de "las dificultades surgidas a lo largo de los años para resolver sus recurrentes diferencias" (de las partes) y el hecho de que "el Plan de Arreglo no incluía ningún mecanismo para hacerlo cumplir", formuló la sorprendente afirmación de que "es indispensable que las partes ofrezcan ahora soluciones específicas y concretas para los múltiples problemas relacionados con la aplicación del Plan que puedan convenirse, $o$ bien estén dispuestas a estudiar otros medios para lograr una solución pronta, duradera y convenida de la controversia relativa al Sahara Occidental" (cursivas mías). ${ }^{10}$ Esta frase originó un intenso debate en el Consejo de Seguridad, pues algunos de sus miembros denunciaron que suponía un intento de "enterrar" el plan de paz y promover una llamada "tercera vía", que no era sino la integración en Marruecos bajo la fórmula de una no precisada autonomía, algo que ya había aceptado mucho antes Hassán II, dicho sea de paso. Este (primer) intento de enterrar el plan de paz fracasó. En efecto, en la subsiguiente resolución del Consejo de Seguridad de 31 de mayo de 2000, éste, si bien en su preámbulo declaró que acogía "con beneplácito" el informe del secretario general de 22 de mayo de 2000 y que hacía "suyas" las "observaciones y recomendaciones" en él contenidas, en la parte dispositiva solicitaba

prorrogar el mandato de la MINURSO hasta el 31 de julio de 2000, con la expectativa de que las partes presentaran al Enviado Personal del Secretario General las propuestas concretas y específicas en que convengan para solucionar los múltiples problemas relacionados con la aplicación del Plan de Arreglo, y examinarán todos los medios para lograr una solución pronta, duradera y convenida de la controversia respecto del Sahara Occidental. ${ }^{11}$

9 Véanse, muy especialmente, los artículos 9.1.iii, 10.b, 12.a del Protocolo "Procedimiento de recursos..." y los artículos 5, 21.b y 22 del Protocolo "Directivas operacionales...".

10 S/2000/461, para. 28.

11 S/RES/1301 (2000) para. 1 
La diferencia entre la recomendación del informe del SG y el dispositivo de la resolución del Consejo de Seguridad es sutil, pero importantísima: lo que en el informe del SG era una alternativa ("o bien") entre el plan de paz y "otros medios", en la resolución del Consejo se convierte en algo distinto, por cuanto la búsqueda de vías para llegar a una "solución pronta, duradera y consensuada" no puede hacerse abandonando el plan de paz ("y").

Tras este fracaso del intento de enterrar el plan de paz, el Consejo alentó nuevas conversaciones directas entre las partes, con la mediación nuevamente de James Baker III, llevadas a cabo en Londres en junio del año 2000. El fracaso de las conversaciones de Londres llevó al SG en su siguiente informe, de 12 de julio de 2000, a repetir su intento, de forma más audaz esta vez. De esta suerte, por un lado y por primera vez, invitaba al Consejo a reflexionar sobre la forma de asegurar el cumplimiento por las partes del resultado del referéndum. ${ }^{12}$ Sin embargo, por otro lado, ante el bloqueo de la situación (cuya responsabilidad de forma incorrecta reparte entre las partes silenciando que la clave es el rechazo de Marruecos a que las apelaciones sean tratadas de la forma pactada) proponía cuatro alternativas, que pueden reconducirse a dos: por una parte el plan de paz ("un acuerdo negociado que permitiese la ejecución exitosa del plan de arreglo"), por la otra una solución política entre los contendientes al margen del plan de arreglo. Esta segunda alternativa (nuevamente, el SG plantea una alternativa), consistente en un "acuerdo negociado" (se supone que entre los representantes de las partes) puede tener un triple contenido: "plena integración en Marruecos", "plena independencia" o "una posición intermedia". ${ }^{13}$ Nuevamente, el Consejo de Seguridad, en su resolución de 25 de julio de 2000, evitó caer en una tentación de consecuencias impredecibles. Como en su resolución anterior, en el preámbulo de la misma acogía "con beneplácito" el informe, pero esta vez omitió incluso en el preámbulo hacer "suyas" las observaciones y recomendaciones que contenía. Por lo demás, el dispositivo de la resolución vuelve a formularse de modo copulativo ante la expectativa de unas nuevas conversaciones directas entre las partes bajo los auspicios del enviado personal del secretario general "a fin de tratar de resolver los múltiples problemas relativos a la aplicación del Plan de Arreglo, y de convenir en una solución política que sea mutuamente aceptable de su controversia res- 
pecto del Sahara Occidental". ${ }^{14}$ La conjunción copulativa utilizada por el Consejo sólo puede interpretarse de una forma, a saber: ante la alternativa del plan de paz y de otro tipo de "acuerdo negociado" de un triple contenido posible, el Consejo confirma (como no puede ser menos) el plan de paz y rechaza la alternativa propuesta por el SG (nuevamente "y"). Como vamos a ver, esta solución era la única posible si no se quería poner en gravísimo riesgo el edificio jurídico del derecho internacional.

\section{Análisis de la cuestión}

El conflicto sobre el Sahara Occidental es un caso paradigmático de descolonización por autodeterminación. El proceso de descolonización varía según cuál sea el principio dominante. Si el principio dominante es el de la unidad nacional y la integridad territorial del Estado, la colonia es considerada como parte de la integridad territorial de un Estado, ${ }^{15}$ por lo que la descolonización se debe producir mediante un "acuerdo negociado" entre dos Estados, el que posee la colonia y aquel a quien se le despojó del territorio de la colonia, para restablecer la integridad territorial perdida. Sin embargo, si el principio dominante es el de autodeterminación, ${ }^{16}$ se parte de que la colonia consiste en un "pueblo" como tal, y el proceso de descolonización se opera con el consentimiento del pueblo colonizado. El reconocimiento de este derecho a la autodeterminación, en consecuencia, es incompatible con la consideración de la colonia como parte integrante de otro Estado.

La Asamblea General de Naciones Unidas muy pronto estimó que el caso del Sahara Occidental no era un supuesto de descolonización para restituir la supuesta integridad territorial perdida de un Estado (en este caso, Marruecos), sino que consideró que se trataba de una descolonización de un pueblo distinto y que debía realizarse mediante el ejercicio por el pueblo saharaui de su derecho a la autodeterminación. Desde la primera resolución adoptada en este sentido en $1966,{ }^{17}$ existe una continuidad ininterrumpida hasta hoy de resoluciones reiterando el derecho a la autodeterminación del pueblo saharaui. Es más, como hace notar el Tribunal Internacional de Justicia, desde 1966 a 1973, Marruecos nunca negó que 
se trataba de un caso de descolonización por autodeterminación y nunca votó en contra de las resoluciones que aprobó en este sentido la Asamblea General de Naciones Unidas, ni alegó que el Sahara Occidental formaba parte de su integridad territorial. ${ }^{18}$ Pero en 1974, por razones políticas diversas, ${ }^{19}$ Marruecos consideraba que no se trataba de un problema de descolonización por "autodeterminación", sino por "reintegración”, es por lo que operó diplomáticamente para detener el referéndum de autodeterminación que iba a organizar España en 1974, consiguiendo que la Asamblea General de Naciones Unidas solicitase al Tribunal Internacional de Justicia un dictamen sobre la cuestión, en última instancia, de cuál de los dos procedimientos de descolonización era pertinente. El resultado del dictamen no deja absolutamente lugar a ninguna duda: el proceso de descolonización del Sahara Occidental está regido por el reconocimiento del derecho a la autodeterminación del pueblo saharaui. ${ }^{20}$ Por las propias características del caso, aunque se trate de una opinión consultiva, el pronunciamiento del Tribunal Internacional debe entenderse como res judicata: el derecho a la autodeterminación del pueblo saharaui no puede ser ignorado, ni negado, ni vulnerado de ningún modo, por ningún órgano de Naciones Unidas. Y así, el Consejo de Seguridad en numerosas resoluciones ha reconocido el derecho a la autodeterminación del pueblo saharaui. ${ }^{21}$

La posibilidad, sugerida en los últimos informes del SG y hasta ahora felizmente no producida, de negar el derecho a la autodeterminación del pueblo saharaui, plantearía gravísimos problemas jurídico-internacionales. En primer lugar, el problema de decidir qué norma prevalecería en caso de conflicto entre una resolución del Consejo de Seguridad que (abandonando su práctica continuada) negara el derecho a la autodeterminación del pueblo saharaui, y las resoluciones de la Asamblea General reconociendo el mismo. En segundo lugar, ya se dicte la nueva norma negando el derecho al pueblo saharaui sólo por el Consejo de Seguridad o

18 ICJ Rep 1975, para. 65.

19 Aquí pueden incluirse desde el inicio de la explotación de los fosfatos en el Sahara Occidental hasta el intento de superar la tremenda crisis política interna (intentos de asesinato de Hassán II en 1971 y 1972) mediante una política nacionalista.

20 ICJ Rep 1975, para. 70 y 161.

21 S/RES/621 (1988); S/RES/658 (1990), que aprueba el Plan de Paz; S/RES/690 (1991); S/RES/725 (1991); S/RES/809 (1993); S/RES/907 (1994); S/RES/973 (1995); S/RES/995 (1995); S/RES/1002 (1995); S/RES/1017 (1995); S/RES/1033 (1995); S/RES/1042 (1996); S/RES/1056 (1996); S/RES/1084 (1996); S/RES/1108 (1997); S/RES/1131 (1997); S/RES/1133 (1997); S/RES/1163 (1998); S/RES/1185 (1998); S/RES/1198 (1998); S/RES/1204 (1998); S/RES/1292 (2000); S/RES/1301 (2000); S/RES/1309 (2000). 
también por la Asamblea General (abandonando también su práctica continuada), se presentarían dos gravísimas cuestiones: de un lado, la de si el acto de un órgano de Naciones Unidas puede contradecir un pronunciamiento del Tribunal Internacional de Justicia reconociendo el derecho; de otro, la de si puede anular arbitrariamente un derecho reconocido en una práctica constante. Respecto al primer problema (conflicto Asamblea General/Consejo de Seguridad), hay que tener en cuenta, por una parte, que las resoluciones de la Asamblea General pueden constituir prueba de derecho consuetudinario, ${ }^{22} \mathrm{y}$, por otra, que sería difícil esgrimir el artículo 12.1 de la Carta, ya que el problema es que antes de que el Consejo de Seguridad se ocupara del tema ya existía una intervención constante y uniforme desde 1967 sobre este particular. ${ }^{23}$ En cuanto al segundo problema (conflicto Asamblea General o Consejo de Seguridad/Tribunal Internacional de Justicia) se ha argumentado poderosamente que el Consejo de Seguridad no está por encima del derecho internacional, sino sometido a él, ${ }^{24}$ por lo que tales eventuales actos implicarían una gravísima vulneración del derecho internacional establecido.

\section{El titular del derecho}

Reconocido el derecho a la autodeterminación del Sahara Occidental podríanos preguntarnos quién es el titular del mismo. La pregunta puede parecer absurda, pero a tenor de las propuestas avanzadas por el SG en los dos últimos informes citados, tiene sentido, pues sólo el titular del derecho puede disponer del mismo. Desde la primera resolución de la Asamblea General de Naciones reconociendo este derecho, se ha considerado como titular del mismo a la "población autóctona" del Sahara Occidental. ${ }^{25}$ El Tribunal Internacional de Justicia, por su parte, también ha expresado con claridad que este derecho a la autodeterminación corres-

22 Akehurst, Michael, Introducción al derecho internacional, trad. de la segunda edición inglesa de Manuel Medina Ortega, Madrid, Alianza, 1972, p. 309.

23 Para prevenir un posible conflicto entre la Asamblea General y el Consejo de Seguridad, el artículo 12.1 de la Carta de las Naciones Unidas estableció: "Mientras el Consejo de Seguridad esté desempeñando las funciones que le asigna esta Carta con respecto a una controversia o situación, la Asamblea General no hará recomendación alguna sobre tal controversia o situación, a no ser que lo solicite el Consejo de Seguridad".

24 Sobre la sumisión del Consejo de Seguridad al derecho, $c f r$. Bedjaoui, Mohamed, "Du contrôle de légalité des actes du Conseil de Securité", en VV.AA., Nouveaux itinéraires en Droit. Hommage à François Rigaux, Bruselas, Bruyllant, 1993, pp. 69 y ss.

25 Resolución AG 2229 (XXI), para. 4. 
ponde a las "poblaciones" del Sahara Occidental. ${ }^{26}$ En consecuencia, no corresponde tal derecho a los "dirigentes", "gobernantes" o "líderes" del Sahara Occidental, sino propiamente a sus poblaciones, esto es, al conjunto de sus habitantes originarios. Sólo el conjunto de estos individuos, y no una parte de los mismos, es titular del derecho y puede disponer del mismo.

Cuestión distinta es la de quién sea el representante de ese pueblo y qué competencias tenga. En efecto, es conocido que ya durante la colonización española una parte del pueblo saharaui se organizó en torno al Frente Popular para la Liberación de Saguia-el-Hamra y Río de Oro (Frente Polisario), fundado en 1973. La misión visitadora enviada en 1975 al territorio por Naciones Unidas en cumplimiento de lo previsto en la Resolución 3292 de la Asamblea General, declaró en su informe que el Frente Polisario era la fuerza política dominante en el territorio. ${ }^{27}$ Poco después, en 1979, la propia Asamblea General, en unas importantísimas resoluciones, consideró al Frente Polisario como "representante del pueblo del Sahara Occidental". ${ }^{28}$ Consecuentemente, estimó al Frente Polisario como la otra parte del conflicto y conminó a las dos "partes" (Marruecos y Frente Polisario) a entablar "negociaciones directas" para llegar a un acuerdo. La práctica de Naciones Unidas ha sido continuada e inequívoca desde entonces, considerando al Frente Polisario como único representante del pueblo del Sahara Occidental y como único interlocutor válido de Marruecos. Quedaba así definitivamente desechada la tesis marroquí, según la cual, el conflicto del Sahara es un conflicto no entre Marruecos y el Polisario, sino entre Marruecos y Argelia. Sin embargo, que el Frente Polisario sea el "representante del pueblo saharaui" y que sea quien entabla "negociaciones directas" con Marruecos no significa que sea el titular del derecho a la autodeterminación y que pueda, por ello, disponer del mismo. De ahí que las propuestas formuladas por el SG en sus últimos informes de considerar como una alternativa al referéndum un "acuerdo negociado" (negociado, necesariamente, por los representantes de las partes en conflicto) suponga un giro peligrosísimo. En efecto, el derecho a la autodeterminación (del que puede predicarse un ca-

26 ICJ Rep 1975, para.161 y 162.

27 Informe del Comité especial encargado de examinar la situación con respecto a la aplicación de la declaración sobre la concesión de la independencia a los países y pueblos coloniales, vol. III (XXX-suplemento núm. 23), Naciones Unidas, Nueva York, 1977, para. 231-237.

28 Resolución AG 34/37, de 21 de noviembre de 1979 (para. 7). Este pronunciamiento se reitera en la resolución AG 35/19, de 11 de noviembre de 1980 (para. 10) y en textos posteriores. 
rácter constituyente) sólo corresponde al pueblo, no a los representantes. La eventual aprobación por el Consejo de Seguridad de una propuesta de ese carácter presentaría problemas gravísimos a los que ya se ha hecho alusión: colisión entre las resoluciones consolidadas sobre el particular del Consejo y la nueva, colisión entre resoluciones de la Asamblea General y del Consejo de Seguridad, colisión entre actos de cualquiera de estos órganos y una decisión del Tribunal Internacional de Justicia.

\section{El ejercicio del derecho}

Si consideramos que el pueblo del Sahara Occidental es titular de un derecho a la autodeterminación, se plantea la cuestión de cómo puede ejercerse este derecho. Este problema es distinto del relativo a cuál sea el contenido de la autodeterminación. Como es sabido, en los supuestos de descolonización por autodeterminación, el pueblo colonizado tiene varias opciones: convertirse en un Estado independiente y soberano, asociarse libremente a un Estado independiente distinto, integrarse plenamente en otro Estado independiente ${ }^{29}$ o asumir "cualquier otra condición (estatuto) política". ${ }^{30}$ Pero si el resultado final del proceso descolonizador por autodeterminación puede ser muy diverso, las normas generales sobre la descolonización previenen un procedimiento único para llevar a cabo esta elección. Así, la libre asociación debe ser resultado de una "elección libre y voluntaria de las poblaciones del territorio en cuestión, expresada según métodos democráticos"; 31 la integración debe resultar "del deseo libremente expresado de las poblaciones del territorio, plenamente conscientes del cambio de su estatuto", siendo hecha la elección mediante "métodos democráticos... imparcialmente aplicados y fundados sobre el sufragio universal de los adultos", siendo posible para la ONU controlar la aplicación de esos métodos; ${ }^{32}$ y la creación de un Estado independiente o la ad-

29 Resolución AG 1541 (XV).

30 Resolución AG 2625 (XXV).

31 Resolución AG 1541 (XV), Anexo, principio VII: “a) La libre asociación debe ser el resultado de la libre y voluntaria elección de los pueblos del territorio interesado expresada con conocimiento de causa y por procedimientos democráticos".

32 Resolución AG 1541 (XV), Anexo, principio IX: "La integración debe producirse en las condiciones siguientes: a) El territorio que se integra debe haber alcanzado un estado avanzado de autonomía y poseer instituciones políticas libres, de modo que sus pueblos estén en condiciones de decidir, en forma responsable, con conocimiento de causa y por procedimientos democráticos. b) La integración debe ser el resultado de los deseos libremente expresados de los pueblos del territorio, plenamente enterados del cambio de su estatuto, con conocimiento de causa y por procedimientos democráticos, aplicados imparcialmente y fundados en el sufragio universal de los adultos". 
quisición de cualquier otro estatuto político debe ser "libremente decidida por (el) pueblo". ${ }^{33}$ El Tribunal Internacional de Justicia ha interpretado estas cláusulas como expresivas de la "necesidad fundamental de tomar en cuenta los deseos/votos (wishes/voeux) de la población afectada", aclarando que la "validez del principio de autodeterminación, definido como la necesidad de respetar la voluntad libremente expresada de los pueblos, no está afectada por el hecho de que en ciertos casos la Asamblea General no haya creído su deber exigir la consulta a los habitantes de tal o cual territorio". Para el Tribunal, "estas excepciones se explican bien por la consideración de que una cierta población no constituía un 'pueblo' habilitado para ejercer la autodeterminación, bien por la convicción de que una consulta sería totalmente innecesaria a la vista de circunstancias especiales". ${ }^{34}$

A la luz de la premisa según la cual la población saharaui ha sido reconocida como un "pueblo" habilitado para ejercer la autodeterminación a través de un referéndum continuada e ininterrumpidamente solicitado por los órganos fundamentales de Naciones Unidas, la Asamblea General y el Consejo de Seguridad, la conclusión se impone por sí misma. Tanto las normas generales sobre la descolonización como el pronunciamiento del Tribunal Internacional de Justicia en el caso del Sahara Occidental, a nuestro juicio, impiden cualquier otro ejercicio del derecho que no pase por el referéndum de autodeterminación. La alternativa a este referéndum, preconizada en los últimos informes del SG, consistente en un "acuerdo negociado" entre las partes, es decir, entre sus "representantes", constituye una peligrosa y poco meditada innovación en el derecho internacional contraria a la práctica constante de las Naciones Unidas, a las normas generales esenciales sobre la descolonización (que gozan del carácter de ius cogens) y al pronunciamiento irrevocable del Tribunal Internacional de Justicia que tiene, por tanto, fuerza de "cosa juzgada" en el caso del Sahara Occidental. La aprobación de tal alternativa por el Consejo de Seguridad plantearía los mismos serios problemas ya referidos al tratar de la cuestión del reconocimiento del derecho y de su titular. 


\section{LA ESTATALIDAD DE LA REPÚBLICA ÁRABE SAHARAUI DEMOCRÁTICA}

\section{Los intentos de Marruecos de anular la estatalidad de la RASD}

Como resultado de la presión ejercida por Marruecos sobre España, materializada en la invasión militar efectuada por la frontera noreste y por la invasión de civiles por la frontera noroeste, el 14 de noviembre de 1975 se firmaron los Acuerdos de Madrid entre España, Marruecos y Mauritania. Contra lo que ha sostenido Marruecos, la simple lectura del acuerdo revela que en el mismo no se transfiere la soberanía del territorio; lo que se estableció fue el procedimiento de abandono de España, y a tal efecto se instituyó una administración temporal tripartita (España-Marruecos-Mauritania), que debía concluir el 28 de febrero de 1976. Los acuerdos nada dicen de qué sucederá concluida la administración temporal tripartita. Pues bien, el 28 de febrero de 1976, al concluir esta administración temporal tripartita en un acto de enorme inteligencia jurídica, se funda la República Árabe Saharaui Democrática en un lugar del territorio. El nuevo Estado fue recibiendo diversos reconocimientos de Estados de los cinco continentes, más de setenta, siendo el último país que reconoció a la RASD Paraguay, el 9 de febrero del año 2000. En este proceso de reconocimiento constituyó un hito la admisión del Estado saharaui como miembro de pleno derecho en el seno de la OUA (Organización para la Unidad Africana) en la cumbre de Addis Abeba en 1982.

Marruecos ha perseguido anular internacionalmente la estatalidad del pueblo saharaui desde su misma fundación desplegando una intensísima actividad diplomática. Esta ofensiva marroquí se despliega en dos líneas: mediante la primera, se trataba de impedir los reconocimientos o intentando su retirada o suspensión; con la segunda se intentaba la expulsión de la RASD de la OUA. Por lo que respecta a la primera línea de actuación, si bien durante los años setenta y ochenta Marruecos no pudo impedir la corriente de reconocimientos, lo cierto es que a partir de la aprobación del plan de paz la política marroquí empezó a dar frutos consiguiendo, de un lado, casi la paralización del proceso (en los años noventa menos de cinco Estados han reconocido a la RASD) y, de otro, si no la retirada del reconocimiento de la RASD, sí la "congelación” del mismo a la espera del resultado del referéndum de autodeterminación que, paradójicamente, el propio Marruecos intenta impedir a toda costa. En este último sentido, Marruecos 
ha conseguido que varios Estados hayan congelado su reconocimiento de la RASD a la espera de conocer el destino final del pueblo saharaui tras el referéndum de autodeterminación. ${ }^{35}$

En su segunda línea de actuación, Marruecos ha pretendido expulsar a la RASD de la OUA. Inicialmente, Marruecos, miembro fundador de la OUA, se retiró de la misma en 1984 pretendiendo presionar a la organización en el sentido de que sólo se reincorporaría si la RASD (Estado de mucho menor peso que Marruecos) fuese expulsada de la misma. Dado que Marruecos no participa en la organización, los intereses marroquíes son defendidos por un grupo de Estados francófonos del África subsahariana que constituyen un auténtico lobby o grupo de presión franco-marroquí (Senegal, Gabón, Burkina Fasso, el Zaire de Mobutu). El grupo de presión marroquí ha tratado de plantear la cuestión de la expulsión de la RASD, siendo en la cumbre de jefes de Estado y de Gobierno Ouagadougou (capital de Burkina, precisamente) de junio de 1998 cuando se produjo la primera gran ofensiva diplomática en ese sentido, renovada en la sesión del Consejo de Ministros reunida en marzo de 1999 en Addis Abeba. Sin embargo, los intentos han fracasado hasta ahora.

\section{Análisis de la cuestión}

\section{A. Los elementos de la estatalidad de la RASD}

Según la teoría clásica (o estática) del Estado, éste se compone de tres elementos: pueblo, territorio y poder. Es decir, un Estado se define por el ejercicio de un poder soberano sobre una determinada población en un determinado territorio. El análisis de cada uno de los tres elementos nos lleva a una conclusión inequívoca.

35 En América han congelado su reconocimiento de la RASD hasta la celebración del referéndum de autodeterminación nueve Estados (por orden cronológico): Perú, El Salvador, Honduras, Guatemala, Dominica, Santa Lucía, Costa Rica, Paraguay y Nicaragua; mantienen su reconocimiento diecisiete Estados (por orden cronológico de la fecha de reconocimiento): Panamá, Granada, Guyana, Jamaica, México, Cuba, Venezuela, Bolivia, Ecuador, Colombia, República Dominicana, Trinidad y Tobago, Belice, St. Kits y Nevis, Antigua, Barbados. En África han retirado su reconocimiento nueve Estados: Benin, Guinea Bissau, Togo, Congo, Sao Tomé y Príncipe, Swazilandia, Burkina-Fasso, Liberia y Chad; lo mantienen veintitrés: Madagascar, Burundi, Argelia, Angola, Mozambique, Ruanda, Seychelles, Tanzania, Etiopía, Cabo Verde, Ghana, Uganda, Lesotho, Zambia, Sierra Leona, Libia, Botswana, Zimbabwe, Mali, Mauritania, Nigeria, Namibia y Malawi. En Oceanía, ha retirado su reconocimiento el Estado de las Islas Salomón y lo mantienen: Vanuatu, Tuvalu, Kiribati, Nauru. En Asia, lo ha retirado la India y lo mantienen: la RDP de Corea, Yemen, Vietnam, Camboya, Laos, Afganistán, Irán, Siria, Papúa-Nueva Guinea. En Europa lo mantienen Albania y Yugoslavia. 
El territorio de la RASD es claro que es el correspondiente al antiguo Sahara español en sus fronteras definidas por diversos tratados internacionales. Este territorio actualmente se halla dividido en dos: el ocupado por Marruecos (y por Mauritania, que mantiene, con consentimiento saharaui, la ciudad de La Güera), que es el comprendido al oeste de los muros, y que es la mayor parte del mismo (quizá hasta un 85\%); y el liberado, en el que ejerce su dominio la RASD, que se encuentra al este de los muros. A este respecto, es ocioso aludir al estatuto del territorio sobre el que se asientan los campamentos de refugiados, enclavado en Argelia, que está cedido temporalmente a la RASD.

El pueblo saharaui tiene unos claros rasgos diferenciales de carácter objetivo y cuenta también con una indiscutible conciencia subjetiva de ser tal pueblo. Este pueblo, que ha sido censado, primero por España y ahora por Naciones Unidas, está distribuido en los tres espacios antedichos: el territorio ocupado (al oeste del muro), el liberado (al este del muro) y el cedido provisionalmente para la ubicación de los campamentos de refugiados argelinos. A ello cabría añadir, naturalmente, que existe población saharaui también en otros lugares (como España o Mauritania).

La soberanía de la RASD se manifiesa en la articulación de una estructura jurídico-administrativa que se proyecta sobre los dos elementos anteriores: territorio y población. De un lado, se ejerce plenamente sobre los territorios saharauis liberados (al este del muro) y, provisionalmente, sobre los territorios cedidos para acoger los campamentos de refugiados. De otro lado, toda la población de los territorios liberados (al este del muro) y del territorio sobre el que se asientan los campamentos de refugiados, acata sin discusión la soberanía de la RASD.

El principal argumento esgrimido para denegar el reconocimiento a la RASD ha sido que no se encuentra en la misma el elemento del territorio dado que en el territorio dominado por Marruecos no se ejerce la soberanía de la RASD. Pero esto no es exacto. En primer lugar, las propias Naciones Unidas han refrendado la división del Sahara Occidental en dos territorios: el que se halla al oeste del muro (ocupado) sobre el que ejercer su soberanía Marruecos y el que se encuentra al este del muro de arena (liberado) sobre el que ejerce su soberanía la RASD. Así se constata en numerosos documentos empezando por el propio plan de paz que ha consagrado documentalmente, y así se ha verificado por tropas de la ONU, que el ejército saharaui domina en los territoros liberados. En efecto, una de las cláusulas del Plan es que las tropas saharauis quedarían acantona- 
das en seis puntos, al este de los muros, pero todos ellos situados dentro del territorio del Sahara Occidental (Zug, Agüenit, Miyec, Mejeiris, Tifariti y Bir Lehlú). Las propias Naciones Unidas son, por tanto, testigos de que en tales puntos del territorio del Sahara Occidental no es Marruecos, sino la RASD, quien ejerce soberanía sobre el pueblo saharaui. Esta clara diferenciación entre el territorio al "oeste" y al "este" del muro de arena se encuentra en muchos otros documentos de Naciones Unidas, fundamentalmente en los informes del SG sobre la situación que son bienvenidos o hechos suyos por el Consejo de Seguridad. ${ }^{36}$ Pero además, en segundo lugar, existe una práctica internacional confirmada de reconocer Estados que no dominan todo el territorio que corresponde a sus fronteras reconocidas. Así ha sucedido en el conflicto de los Balcanes, que ha mostrado cómo los Estados europeos, y la comunidad internacional en particular (incluida la ONU), han reconocido a Estados que no dominaban todo el territorio contenido de sus fronteras internacionales (Croacia y Bosnia-Herzegovina, son ejemplos elocuentes).

\section{B. La RASD y la OUA}

Como se ha dicho, una de las líneas de ataque de la diplomacia marroquí se dirige hacia la OUA pretendiendo la expulsión de la RASD de la misma. Ahora bien, dado que la Carta de la OUA no contempla la posibilidad de expulsión de un Estado miembro, los esfuerzos se dirigen a probar que la admisión fue nula. La argumentación marroquí, canalizada a través de Senegal y expresada por labios del ministro de Relaciones Exteriores de este país, Jacques Baudin, se despliega en dos sentidos: por un lado, estima que la admisión de la RASD fue contraria a la Carta de la Organización (artículos 4, 27 y 28); por otro, que una entidad que va a un referéndum de autodeterminación para conocer su status. Analizaremos ahora la primera cuestión, y en el siguiente epígrafe examinaremos la segunda. La Carta de la $\mathrm{OUA}^{37}$ regula tanto la cuestión de quién puede ser

36 Por mencionar únicamente los textos posteriores a los acuerdos de Houston, $c f r$. S/1997/742, de 24 de septiembre (acuerdos de Houston, aprobados por resolución de Consejo S/RES/1133), Anexо II; S/1997/882, para. 19; S/1998/634, para. 9; 17; S/1998/775, para. 8; S/1998/849, para. 12; S/1998/997, para. 8, 11, 12, 14; S/1998/1160, para. 15; S/1999/307, para. 13, 15; S/1999/483, para. 12; S/1999/721, para. 8; S/1999/954, para. $10 \mathrm{~S} / 1999 / 1098$, para. 13, 18, 22, 23; S/1999/1219, para. 14, 18, 22; S/2000/131, de 17 de febrero, para. 13, 14; S/2000/461, de 22 de mayo, para. 21, 22; S/2000/683, de 12 de julio, para. 20, 23.

37 Carta de la Organización para la Unidad Africana, firmada en Addis Abeba el 25 de mayo de 1963. 
miembro de la Organización como la de qué procedimiento se sigue para proceder a la admisión. La primera cuestión, a saber: quién está habilitado para ser miembro de la Organización, se halla resuelta en el artículo 4o. de la Carta de la OUA, que dice que "todo Estado africano, independiente y soberano podrá convertirse en miembro de la Organización". A la luz de las consideraciones anteriores, creemos que este punto no ofrece ninguna duda y que está clara la condición de la RASD como "Estado" (que cumple los tres requisitos de la doctrina clásica) que además es "independiente" y es "soberano", pues no es un miembro de una federación ni se halla sometido a régimen de protectorado. La segunda cuestión, esto es, la de qué procedimiento debe seguirse para que un "Estado africano independiente y soberano" pueda ingresar en la Organización, tiene su respuesta en el artículo 28 de la Carta de la OUA, que dispone diversas fases. La primera es la petición ("En cualquier momento, cualquier Estado africano independiente y soberano puede notificar al secretario general su intención de adherirse a la Carta", artículo 28.1); la segunda es la comunicación por el Secretario General a los demás miembros ("Al recibir la anterior notificación, el Secretario General enviará una copia de la misma a todos los Estados miembros", artículo 28.2.1); la tercera, es la votación por los miembros ("La admisión se decidirá por mayoría simple de los Estados miembros. La decisión de cada Estado miembro se transmitirá al Secretario General", artículo 28.2.2); y la cuarta y última la admisión y notificación al solicitante (el secretario general, "al recibir el número requerido de votos comunicará la decisión al Estado afectado", artículo 28.2. in fine). Éste es el procedimiento que se siguió para la admisión de la RASD en la cumbre de la OUA de Addis Abeba en 1982.

La ofensiva diplomática marroquí pretende que la admisión de la RASD fue irregular por dos razones: en primer lugar, porque a su juicio la RASD no tendría el título habilitante que requieren los artículos 4o. y 28.1 de la Carta; en segundo lugar, porque, admitiendo que podría haber alguna duda al respecto, debería haber entrado en aplicación el artículo 27 de la Carta de la OUA, que establece que "cualquier cuestión que pudiera surgir acerca de la interpretación de esta Carta se decidirá por mayoría de dos tercios de la Asamblea de Jefes de Estado y de Gobierno de la Organización". La clave está en que, de admitirse la duda sobre la estatalidad de la RASD, la cuestión se tendría que haber resuelto por una mayoría de 2/3 de los miembros que probablemente no se hubiese podido 
alcanzar. Ahora bien, una cosa es que se pueda dudar de la "conveniencia" de que la RASD ingrese en la OUA y otra que se pueda dudar de su carácter de Estado. El secretario general de la OUA en 1982, si bien era consciente de que había Estados que dudaban de la "conveniencia" del ingreso, también lo era de que no había duda que el candidato reunía todos los elementos que conforman un Estado. En definitiva, no creemos que el ingreso de la RASD en la OUA haya sido en modo alguno irregular, a pesar de los constantes esfuerzos de Marruecos por argumentar en este sentido con la intención de que la OUA llegue a declarar el ingreso de la RASD como nulo.

\section{La RASD y el referéndum de autodeterminación}

La segunda línea de ataque de la diplomacia marroquí contra la estatalidad de la RASD se centra en una argumentación que conoce dos variantes: según la primera, al estar el futuro del Sahara pendiente de un referéndum de autodeterminación, no se puede reconocer a una entidad que va a un referéndum para conocer su estatuto; según la segunda, si la RASD ha aceptado el principio del referéndum para poder ser un Estado independiente y soberano, ahí ofrece la prueba de que no es un Estado. El argumento marroquí no sólo ha sido utilizado en general para intentar que otros Estados no reconozcan a la RASD o congelen o retiren el reconocimiento de la misma hasta que se celebre el referéndum, sino que también ha sido esgrimido en el contexto particular africano por Senegal para solicitar la expulsión de la República saharaui de la OUA. Sin embargo, estamos ante unos argumentos falaces. En efecto, en primer lugar, la RASD no ha aceptado el referéndum "para convertirse en un Estado independiente y soberano", sino para recuperar su territorio ocupado (haciendo para ello una apuesta muy fuerte: si no recupera todo su territorio ocupado por Marruecos entregará su propio territorio actual al Estado que no lo posee, a saber: Marruecos) y para hacer posible que una parte de la población saharaui (la que vive en los territorios ocupado por Marruecos y se ve impedida de cruzar el muro de arena) pueda someterse a la República saharaui. Por ello, frente a lo sostenido en el argumento marroquí, el referéndum no persigue "conseguir un Estado", sino "conseguir pacíficamente un territorio ocupado" y permitir a unas poblaciones adherirse a una República a la que ahora no pueden libremente acceder. En segundo lugar, tampoco es cierto que el hecho de que el futuro del Sahara esté 
pendiente de un referéndum signifique que la RASD vaya al mismo para conocer su futuro estatuto internacional, ya se trate de un resultado con victoria, ya se trate de un resultado con derrota. En efecto, en caso de victoria, el referéndum de autodeterminación saharaui no va a alterar el estatuto de la RASD, pues el efecto del mismo sería que el Estado previamente subsistente, la RASD, hace suyo todo el territorio comprendido en las fronteras internacionalmente reconocidas. En caso de derrota, el referéndum de autodeterminación sí que alteraría el estatuto de la RASD, como lo puede hacer cualquier referéndum constituyente por el que se decida la integración plena de un Estado en otro o su integración en una Federación. En tanto en cuanto todos los Estados tienen soberanía, y la RASD también, pueden tomar la decisión de integrarse en otro Estado. Y, sin embargo, nadie ha argumentado que, por ejemplo, los demás Estados deban retirar su reconocimiento internacional del Estado español por el hecho de que, al embarcarse en el proceso de integracón europea, pueda desaparecer si se constituye una Federación europea. La decisión de federarse o de integrarse es una decisión soberana; por ello, si algo pone de manifiesto el referéndum de autodeterminación en el supuesto de derrota de la opción independentista es, precisamente, la soberanía que ejerce la RASD. En definitiva, la autodeterminación es un derecho que pone de manifiesto la soberanía del sujeto que lo ejerce que, en el supuesto de gozar de un territorio propio, debe calificarse como Estado.

\section{CONCLUSIONES}

1a. El pueblo saharaui tiene reconocido su derecho a la autodeterminación por la Asamblea General de Naciones Unidas, por su Consejo de Seguridad y por el Tribunal Internacional de Justicia, por lo que tiene carácter irrevocable y sólo puede agotarse con su ejercicio.

2a. El titular de este derecho sólo puede serlo el pueblo saharaui, sin que pueda ser ejercido por los representantes de él.

3a. El derecho a la autodeterminación del pueblo saharaui sólo puede ejercerse mediante el procedimiento demócratico del referéndum de autodeterminación, sin que sea posible suplir esta técnica por otra del tipo de "acuerdo político".

4a. La República Árabe Saharaui Democrática reúne todas las notas que la doctrina clásica exige para ser reconocida como un Estado: ejerce 
un poder soberano sobre una determinada población asentada en un determinado territorio.

5a. La RASD es un Estado africano, soberano e independiente cuyo ingreso en la OUA fue acorde con las prescripciones de la Carta de la Organización sin que pueda ser anulado.

6a. La celebración de un referéndum de autodeterminación sobre el futuro del Sahara no tiene por objeto la consecución de un "Estado", sino la obtención de una parte del territorio comprendido en las fronteras internacionalmente reconocidas (el territorio ocupado por Marruecos) y permitir a la población del mismo adherirse libremente a la República saharaui o permanecer en su status actual. 